\title{
Thermal Barrier Coating for Application to Light Weight Gas Turbine- A Review
}

\author{
B. Goswami', S.B. Kumar ${ }^{2}$ and A.K. Ray \\ National Metallurgical Laboratory (CSIR), Jamshedpur-831007,India \\ ${ }^{1}$ R.V.S. College of Engineering and Technology, Jamshedpur-831012, India \\ 2. National Institute of Foundry and Forge Technology, Ranchi-834003, India
}

\begin{abstract}
:
Hot section gas turbine implements are subjected to fluctuating stresses and temperatures within aggressive environments. It results in combined fatigue, creep and oxidation of constituent materials. Studies of different types of high temperature fatigue of nickel base superalloys help us to understand the causes of failure and expectations for the prediction of life. Generally nickel base superalloys are used in the form of single crystal, directionally solidified, powder metallurgy products, and polycrystalline cast/wrought alloys for different applications. The high temperature properties of these various forms make interesting usage within different high temperature and aggressive environments under stressed conditions. Gas turbines of either aerospace, electricity or diesel engine sectors are the consumers of these alloys. Thermal profiles of gas turbines are zones of interest for application. Considerations of lightweight philosophies to the implements reduce the section thickness. Therefore evaluation of fatigue for these alloys under stipulation of simulation bears more attention. Creep interposition into fatigue theories has become the basis of interpretation. Experiences to date belong to empiricism, where the formulations require introduction of many suitable variables according to the system of exposure. Application of thermal barrier coatings improves the performances of previous designs. Key failure areas of thermal barrier coatings are thermally grown oxide growth and ceramic coat sinter induced buckling and spallations. These coatings in practice appear in the form of thick, thin, and duplex, laser surface re-melted, functionally gradient materials, and microlaminations. The composite system of materials evaluation corresponds to the requirement of fatigue experiments for life prediction. The objective is to study the comparative behavior of nickel base superalloys under different conditions of fatigue and the influence of the thermal barrier coating (TBC). Different types of fatigue mechanisms experimentally simulate components exposed to services because the variable for interrelation of the physical-thermal-chemical-mechanical phenomenon that prevails in such systems appears to be deficient.
\end{abstract}


Key words: Ni-base superalloys, Compositions, Creep, Fatigue, Thermal barrier coating, Gas turbine, Life prediction, Combustor

\section{INTRODUCTION}

The development of Ni-base superalloys for high temperature application is based on a solid technical foundation and has significant practical importance. Major developments in $\mathrm{Ni}$-base superalloys have been stimulated by the demand for a suitable material that can be capable of withstanding the thermo-mechanical thermo-chemical changes upon exposure to high temperature. The stringent requirements for high temperature application of Ni-base superalloys have been met as our knowledge has increased significantly about the inter-relationships between microstructure and high temperature properties. The search for improved high temperature alloys will continue but perhaps with more difficulty as attempts are made to take advantage of every last vestige of high temperature properties. In recent years it has been possible to use multiple regression analysis to relate quantitatively the microstructure to the high temperature properties in a number of Ni-base superalloys. Attempts have been also made to quantify semi-empirical structureproperties relationships using computational techniques based on models. The most striking development in recent years is the application of thermal barrier coatings on Ni-base superalloys. Thermal barrier coatings are not only effective in improving the high temperature properties of $\mathrm{Ni}$-base superalloys but are also less expensive. In recent years conscientious attempts have been made to extend the life performance and efficiency of $\mathrm{Ni}$-base superalloys used in aerospace engines which operate at a temperature beyond their melting point through the application of thermal barrier coatings. However the beneficial effects of thermal barrier coatings have not yet been fully appreciated although attempts have been made to explore and understand the atomistics of flow and fracture in these coatings. It is believed that the diverse and complex high temperature deformation phenomena such as fatigue, creep, oxidation and corrosion often lead to their premature failure; the emphasis of this paper has been to include the maximum scope of fatigue behavior of $\mathrm{Ni}$-base superalloys in a fairly comprehensive way. Fatigue failure in Ni-base superalloys proceeds in a gradual and stable way leading to brittle fracture. It occurs without any obvious warning after a considerable period of use. Several mechanisms have been proposed about the initiation of a fatigue crack and its subsequent growth in Ni-base superalloys. However, reliable prediction of fatigue failure in Ni-base superalloys has not been successful so far as we are far away from a quantitative theory which relates elementary processes to the observable life under fatigue loading. Nevertheless, considerable progress has been made in the past two intervening decades in the understanding of the physical mechanisms of fatigue in $\mathrm{Ni}$-base superalloys. This will be the subject of concern in the present paper; a systematic approach has been made to disentangle the separate combinations of different types of fatigue leading to fracture particularly in $\mathrm{Ni}$-base superalloys. 
The philosophy of lightweight gas turbine (GT) implements under combustion environment lays emphasis on high temperature resistant alloys and thermal barrier coating systems. The usage temperatures are conceptualized through various simulated laboratory tests. The performance of the interface between the ceramic coat and the metallic bond coat is considered as a limiting factor to the evaluation $/ 1,2 /$. Interfacial mismatch stress relaxation for bond coated substrates manifests as a rumpling phenomenon /3, 4/. Rumpling is an energy release process associated with increment of metal surface area of bond-coated surface without a topcoat. In case of ceramic-coated substrate with a metallic bond coat, the ductile to brittle transition temperature responds to rumpling in terms of microcrack formation at the ceramic-metal interface. Bond coat on aging fails after increase in the thickness of brittle thermally grown oxides (TGO). Depletion of valuable constituents degrades bond coat properties $/ 5 /$. Additive substrate degradation originates from crack wedging effects of the oxide coating.

The effects of various parameters using different simulations of mechanical or thermal or thermomechanical fluctuations with associated corrosion have been studied. An empirical high temperature fatigue experience encompasses the equilibrium between strain hardening process and recovery process. If the recovery process is slower the failure occurs by fatigue mechanisms, whereas if the strain-hardening rate is slower then failure occurs by creep processes.

The test recommended for liners of gas turbine combustor is the fluctuating or repetitive stress under isothermal and the high frequency fatigue test. The hardening effects for such alloy systems and the associated transgranular failure at a high temperature are caused by elemental depletion and segregation of constitutions in alloys due to a fluctuating stress in contradiction to cyclic stress $/ 6,7 \%$. Thermo-mechanical fatigue of blades shows inter-granular oxidation. Microstructure stability for creep and fatigue strength of nickel-base superalloys has been achieved through an alloy design in which grain boundary active elements play a competitive role in the activity between the carbide forming tendency and oxidation/corrosion protection tendencies.

Different types of fatigue experiments have been briefly discussed. Thermo-mechanical fatigue, creepfatigue and thermal fatigues are major types of fatigue that take place in gas turbine components. Deficiency of interpretation stands on the relative contribution of different factors that lead the system to failure. Proper simulation complicates the selection of variables so as to apply them within empiricism. Neural diagrams are one of the new approaches for creep-fatigue life estimations for specimens of thicker section.

TBC coated samples display an improved performance. However, failure in TBC seems to be due to interconnected porosity and roughness of the interface $/ 8$. Silica appears to be an active contaminant to form low melting eutectics at the interface of the ceramic topcoat and metallic bond coat. Reduction of silica below $1 \%$ in the composition of yttria stabilized zirconia thermal barrier coatings increase the life by five times in thermal fatigue $19 /$. 


\section{FATIGUE CRACK FORMATION}

Nickel base superalloys have been used with high reliability for blades and vane applications in gas turbines for the last decade. The application of directionally solidified and single crystal alloys has become common in advanced gas turbines because of their superior creep and fatigue properties compared to conventionally cast polycrystalline materials. Regarding such materials several kinds of studies, such as the effects of temperature, loading frequency, stress multiaxiality, environment, microstructure, and crystallographic orientation on the fatigue and creep strengths have been performed. Current works on fatigue crack propagation at room temperature emphasize the study of small or short cracks of the order of microns. The greater part of life is generally dominated by small crack initiation and propagation. Hence it is directly connected with the life prediction. Since small cracks grow with a propagation rate that is significantly higher than that of accompanying physically long cracks, the life prediction based on the traditional long crack results involves strong potential for non-conservative estimation. Small crack growth is notably affected by microstructures, such as grain boundary and strengthening precipitates and by the environment, i.e. long cracks. The problem of small cracks in creep-fatigue of nickel base superalloy is serious in nature since the thickness of a gas turbine blade itself is in the order of millimeters. Nevertheless, there is very little or inadequate information on the small crack growth process under creep-fatigue conditions. The effect of the environment on the creep-fatigue small cracks is also a problem to be understood $/ 10 \%$. At the scale of the microstructure, the instantaneous rate of fatigue crack growth is governed by the crack path selection mechanism. A statistical analysis of crack arrest, instantaneous crack growth rates and their dependence on linear elastic fracture mechanics parameters is required. It is shown that all fatigue crack growth events occurring at the microstructure scale can be represented by a few statistical distributions. Analysis of the underlying slip band and dislocation mechanism of conventional fatigue in nickel base superalloys is essential /11/. High temperature 'dwell cracking' of the nickel base superalloy IN 718 has been investigated. Dwell and fatigue crack growth tests under simple loading conditions indicate that dwell cracking would be unlikely to occur under actual flight loading. Standard fracture mechanics may be inappropriate for predicting crack growth. Flight by flight loading tests showed that dwell cracking is either absent or limited. Study has been done about fracture mechanics; characterizations of dwell crack growth; effects of peak loads and underloads on dwell crack growth; fatigue crack growth dwells in standard and engineering specimens and crack growth under flight-by-flight loading all at $600^{\circ} \mathrm{C} / 12 /$.

Crack growth tests have been performed on specimens with rectangular cross section of Inconel 718 at 550 and $687^{\circ} \mathrm{C}$ in order to examine the low cycle fatigue behavior at frequencies of 0.5 and $10 \mathrm{~Hz}$. Symmetric strain-controlled tests with a strain range of $\Delta \varepsilon=1.5 \%$ and load controlled zero tensile tests with a maximum load of $700 \mathrm{MPa}$ have been performed along with additional creep crack growth tests at $687^{\circ} \mathrm{C}$. Fracture surfaces when examined have revealed intergranular mode of fracture at $0.5 \mathrm{~Hz}$ and a combination of inter and trans-granular at $10 \mathrm{~Hz}$. At $550^{\circ} \mathrm{C}$ the fatigue specimens have shown a mixed fracture mode at 0.5 
$\mathrm{Hz}$ and a transgranular fracture mode at $50 \mathrm{~Hz}$. For the fatigued specimens showing an intergranular fracture mode, crack propagation rates as a function of the stress intensity factor range proved to be time-dependent and to be slightly higher than the pure creep crack growth rates. The visco-plastic constitutive equations use experimentally observed crack growth rates as input to a finite element simulation to determine the fraction of crack closure. Crack opening takes place almost immediately upon load reversal from a state of maximum compression /13/. Fracture crack growth rates (FCGR) in a single crystal superalloy PWA 1480, with different crystallographic orientations have been measured at room temperature and at $870^{\circ} \mathrm{C}$ for two stress ratios: $R=-1$, and $R=0.1$. A misorientation between the tensile axis and the [001] crystallographic direction has no effect on the FCGR regardless of the test temperature or stress ratio. The stress ratio also has little effect on the FCGR. At room temperature, the fracture surfaces are highly crystallographic. The change in crack propagation path from a macroscopically mode I crack to large $\{111\}$ facets results in higher growth rates. The observed fracture behavior can be interpreted on the basis of resolved shear stresses on $\{111\}$ planes ahead of the crack tip. At the elevated temperature, fracture is completely non-crystallographic, and FCGRs are only mildly dependent on the direction of propagation $/ 14 /$.

Studies of short-term fatigue growth of Waspalloy at 19 and $600^{\circ} \mathrm{C}$ reveal that the dominant mechanism of crack formation is slip band cracking. Crack formation is also associated with coarse carbide particles within the matrix. The dominant failure mechanism is one of mixed mode-I and -II fracture, with the mode-II shear displacement-giving rise to non-closure induced by surface roughness. Oxide and plasticity-induced non-closure process made only a minor contribution to the overall growth process. Short fatigue crack growth measured at $\mathrm{R}=0.1$ is faster at $500^{\circ} \mathrm{C}$ as compared to $19^{\circ} \mathrm{C}$ at an equivalent value of $\Delta \mathrm{K}_{\mathrm{t}}$. This is attributed to a change in slip character from highly planer to one involving increasing amounts of cross slip at $19^{\circ} \mathrm{C}$ and $500{ }^{\circ} \mathrm{C}$ respectively $/ 15 /$. The cyclic creep studies of a Nimonic 75 type alloy show that at low stress amplitudes and high temperatures the fracture lives of cyclic creep and static creep remain the same. After normalization, all the data are found to obey approximately the linear cumulative law, which means that the change in fracture type does not alter the nature of creep-fatigue interaction $/ 16 /$.

The use of optical crack monitoring system designed to examine the growth behavior of short/long fatigue cracks in Waspalloy at 19 and $500^{\circ} \mathrm{C}$ is demonstrated at stress ratios of 0.1 and -1 . Fatigue crack formation is associated with slip band cracking at both $\mathrm{R}=0.1$ and $\mathrm{R}=-1$, normalized by adopting a positive stress approach. The compressive part of the fatigue cycle at $\mathrm{R}=-1$ contributes to short crack growth at $19^{\circ} \mathrm{C}$ and long crack growth at $500^{\circ} \mathrm{C} / 17 /$.

\section{FATIGUE LIFE PREDICTION}

Models used for thermo mechanical life predictions are based on creep-fatigue interactions exhibited by ductile metals, and do not explicitly contain environmental features. These models use parametric damage 
approaches, in which the environmental effect is incorporated in the time dependence of the formulation /18/. Life predictions based on residual stress relaxation under cyclic loading in which finite element software is used for taking the cyclic plasticity into account have been successfully employed. The computed values of relaxed residual stress distributions do not match with experimental results obtained by $\mathrm{X}$-ray diffraction measurements /19/. Fatigue lifetime is given by the material's creep properties for steady state creep $(r \sim 1)$. For $r>1$ the simple linear life fraction rule for creep damage (AC-rule) overestimates fatigue lifetime. The deviation increases with an increase of $r$ /20/. The method for fatigue life prediction of high temperature polycrystalline materials under high rate fully reversed strain cycles (HRSC) is generalized using a continuous damage mechanics approach. Predictions of fatigue life require the understanding of balanced cyclic creep rupture (BCCR), tensile cyclic creep rupture (TCCR) and compressive cyclic creep rupture (CCCR). The life is evaluated by taking into consideration the interaction of plasticity and creep with the mean applied stress in which crack propagation behavior is controlled by fatigue-creep interaction $/ 21$. It is proposed that the frequency modified total strain energy parameter is useful for evaluating fatigue life and crack initiation life of a high strength superalloy under fatigue-creep interaction (FCI) conditions using the tensile strain energy parameter obtained from the total tensile strain energy and the loading time under tensile stress, where the surface crack propagation rate has been evaluated as a function of crack half-length under FCI conditions. Life prediction has been accounted for in terms of the grain size and the number of cycles needed for the surface crack length to grow with respect to grain size as shown in Figure 1, 122,23/.

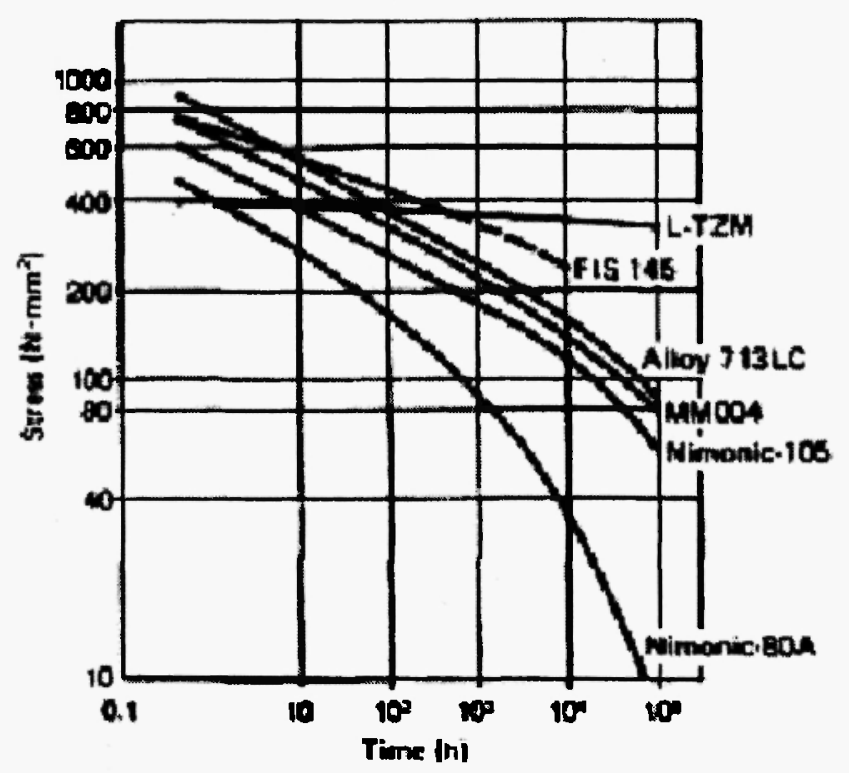

Fig. 1: Creep rupture strength of different turbine blade materials at $850^{\circ} \mathrm{C} / 23 /$. 
Interaction of creep damage and fatigue damage has been developed for the high temperature superalloy $800 \mathrm{H}$. The cavitation damage of internal grain boundaries during creep-fatigue experiments needs a nucleation stage and a growth stage. The growth stage arises for a slow deformation in tension where as the nucleation stage develops in compression. Compression half cycle nucleates cavities. The shorter the time in compression the more nuclei are formed by interfacial decohesion of grain boundary carbides. The lifetime is determined by fatigue crack propagation, whose rate is controlled by factors such as fast athermal deformation, creep deformation in tension and interaction with cavities. These factors contribute in developing a model that is capable for predicting cyclic lifetime for quite different cycle types within a factor of two $/ 24 /$ For creep-fatigue life prediction under the conditions of tension tensile stress the linear cumulative damage rule is adopted. However, a new method has been developed called numerical computational approach of strain energy partitioning (SEP). The results from GH169, GH36 show that the numerical computational approach of SEP has proved better over other prediction methods $/ 25 /$. No matter how carefully manufacturing processes are controlled, defects can still be present in materials going into service and surface damage of some form may be inevitable when components and structures are put into application. Accordingly the damage tolerance approaches is more helpful in monitoring conditions and extend the life of components. The damage tolerance may be defined as the ability of the structure or component to resist failure in the presence of flaw cracks or other damage for a specified period of usage. This method relies on the fracture mechanics used to predict the behavior of cracks growing from origins with size fixed by material process control or non-destructive inspection. Sub-surface defects in the gas turbine aero engine disc may lead to fragmentation within the engine casing, thus hazarding both the aircraft and its passengers. Subsurface defects may be present in forged nickel based alloy discs due to chemical heterogeneity known as white spot, ceramic inclusions and cracked inclusions. When the disc surface has been shot peened and is under residual compressive stresses, such subsurface defects may grow by fatigue or fatigue-creep at operating temperatures before the initiation of surface cracks. The size, shape, orientation, and distance below the surface vary considerably thereby influencing the fatigue crack growth (FCG) behavior and the cycle life $\left(\mathrm{N}_{f}\right) / 26 /$. According to the initial hypothesis defects would crack during the first loading cycle and thereafter the fatigue cyclic life (Nf) would be entirely made up of crack propagation life.

Conventional elevated temperature creep-fatigue life prediction techniques often utilize the same deformation mechanism over a range of extrinsic conditions such as strain levels, frequencies, and dwell times. Time dependent changes in intrinsic materials characteristics, such as grain size and carbide distribution are often not considered. An empirical relationship has been established between the plastic strain range and the fatigue life (cycles to failure) at higher temperature or longer exposure times where the time dependent phenomenon becomes increasingly important. Some improvement in predictive capability is possible through the introduction of a frequency term to account for time dependent effects. The linear life fraction approach assumes that fatigue and creep damage phenomena can be separated into cyclic and time- 
dependent components respectively. When creep and fatigue interact the predicted value falls below the experimental value for each material under specified extrinsic conditions $/ 27 /$.

The significance of mean stress effects for the successful high temperature life prediction approach has been recognized. The mean stress effects arise from time dependent relaxation. This approach assumes that damage measure can be related to the net tensile hysteresis energy corresponding to the area in the hysteresis loop between the mean stress and the ultimate stress associated with crack propagation. This relation can again be modified to include time-dependent damage by the introduction of a frequency term. When the amount of relaxation is different in tension and compression, the wave shape dependence is accounted accordingly for lifetime prediction. There are several limitations associated with the above-mentioned life prediction methods. It does not differentiate between loading cycles with or without hold times or between tension and compression strain rates as long as the frequencies and strain ranges are the same. Similarly, the linear life fraction methodology considers both tensile and compression hold times to be equally damaging not taking into account possible healing effects of the compressive cycle, while the wave shape-dependent method separates tensile and compressive hold times. It only considers a tensile hold time to be damaging, neglecting possible damage caused by compressive holds that result in mean tensile stresses.

\section{HIGH TEMPERATURE CREEP-FATIGUE LIFE PREDICTION BY THE NEURAL NETWORK APPROACH}

Artificial neural network (ANN) has emerged as an alternate powerful problem-solving tool in signal processing, non-destructive testing, process control, corrosion life prediction, and materials science. The architecture of an ANN is based on the human nervous systems. It receives and process information. Each processing element $(\mathrm{PE})$ receives input signals, from the environment or from other PRs and processes the weighted sum of all the inputs through a threshold function.

INCONEL 690 is an excellent candidate for examining the potential applicability and limitations of the neural network approach for creep-fatigue life prediction as it is metallurgical unstable due to carbide dissolution and extensive grain growth above $0.75 \mathrm{~T}_{\mathrm{m}}$ leading to microstructure instabilities which have a major impact on the deformation mechanisms observed during constant stress loading $/ 27 /$.

A simple neural network is represented in Figure 2, where the interest is to simulate TBC on a thin section gas turbine component $/ 28 \%$. 


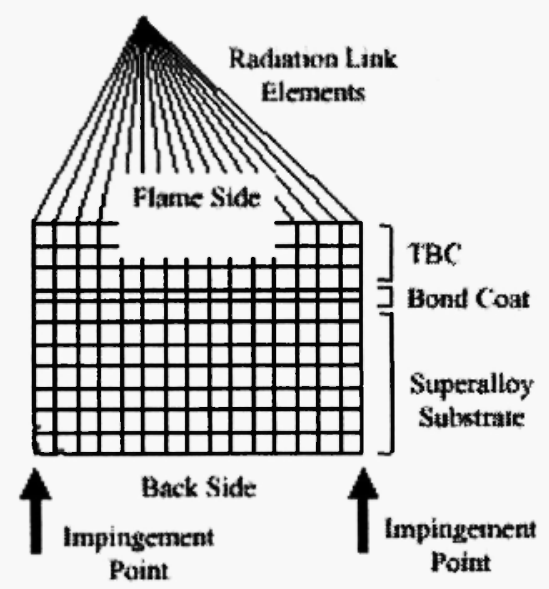

Fig. 2: ANSYS finite element model $/ 28 /$.

\section{EMPIRICAL MODIFICATIONS OF COMPOSITION}

Nickel base superalloy compositions of improved properties can be obtained through multiple regression analysis using the published material data of superalloys. The estimated equations are established to calculate the mechanical properties such as stress rupture strength, tensile properties, and physical properties such as density and thermal conductivity. An alloy design program by statistical methods to select the alloy chemical compositions, which satisfy the requirements of structural design has been developed. Using the alloy design method several superalloys have been developed. The new nickel-base superalloys developed through statistical alloy design have good workability and good mechanical and physical properties /29-38/.

Among the commercially available superalloys, 718 stands out as the most dominate alloy in production as it currently accounts for as much as $45 \%$ of wrought nickel based alloy production and $25 \%$ of cast nickel based products. The focus is on 718's status in four key areas, clean melt practice, resistance to low cycle fatigue, thermo mechanical processing and alloy optimization $/ 39 /$.

Rolled alloys (Tables 1 to $4 / 40 /$ ) represent different mechanical and physical properties of nickel base superalloys. The exposure at different temperatures and thermo mechanical treatments on sheet form are illustrated in response to gas turbine components. 
Table 1

Data of rolled alloys for flying and land based turbine market- The RA625

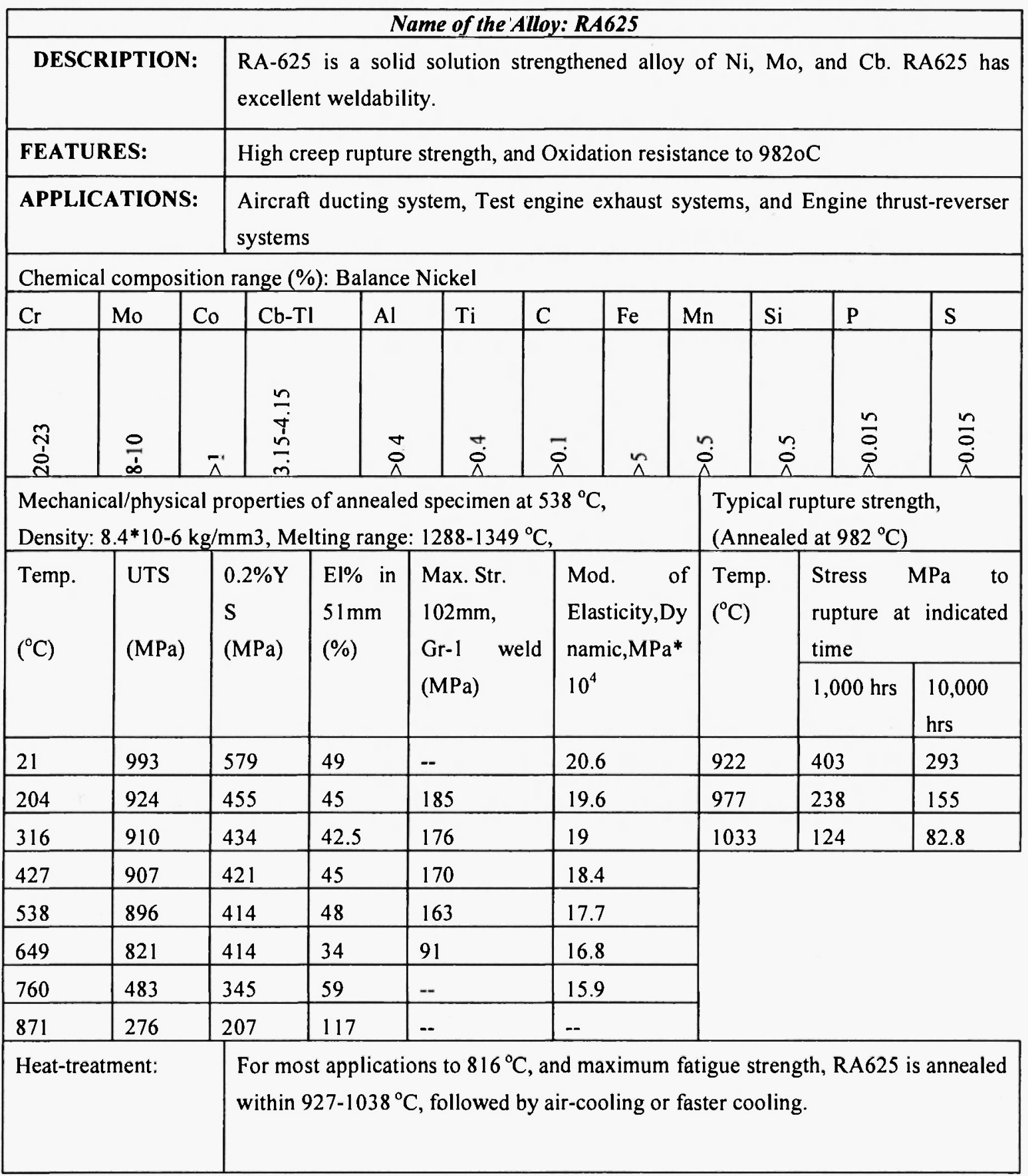


Table 2

Data of rolled alloys for flying and land based turbine market-The Rene 41 [40]

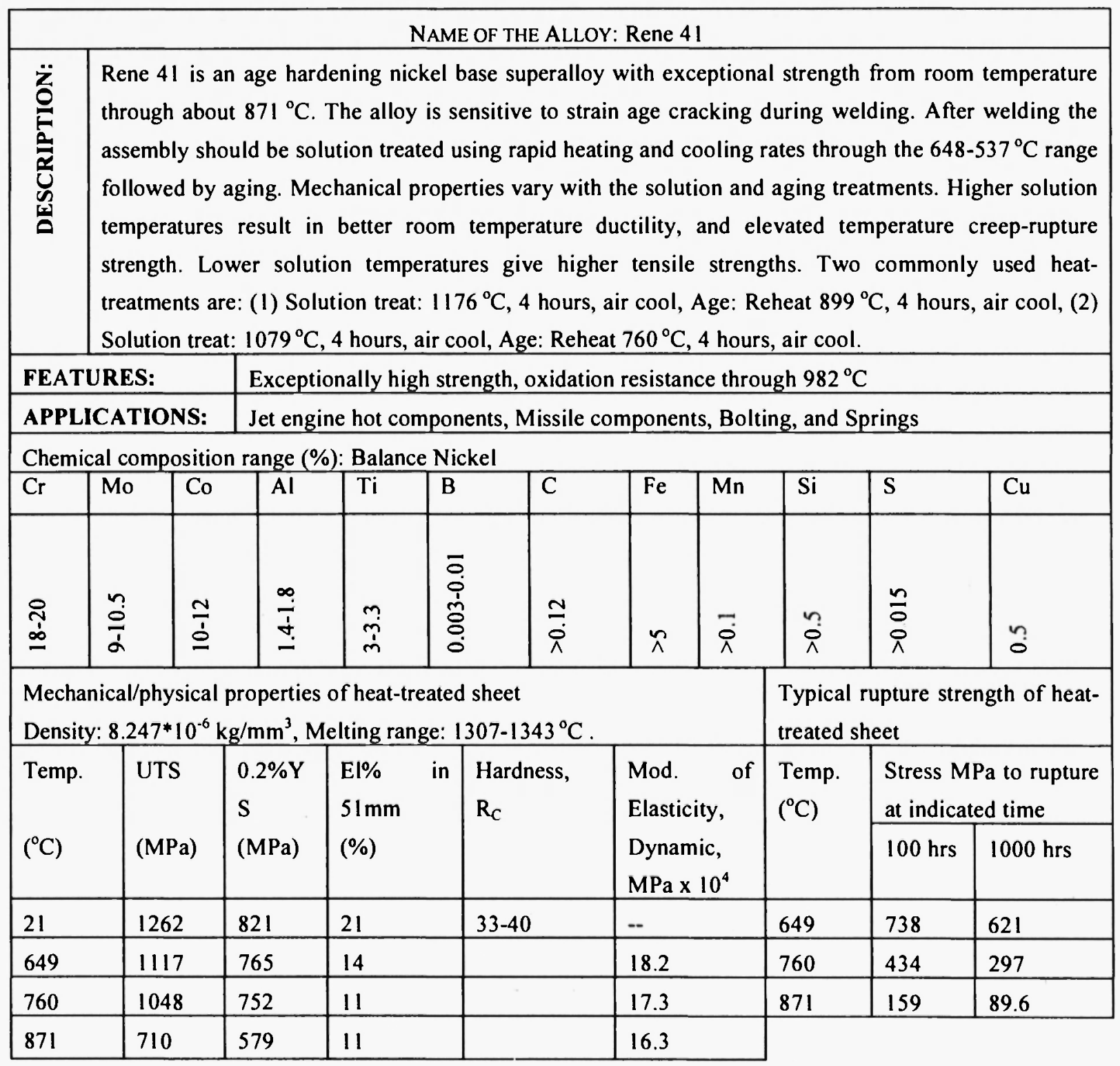


Table 3

Data of rolled alloys for flying and land based turbine market- The WASPALOY [40].

\begin{tabular}{|c|c|c|c|c|c|c|c|c|c|c|c|c|}
\hline \multicolumn{13}{|c|}{ NAME OF THE ALLOY: WASPALOY } \\
\hline 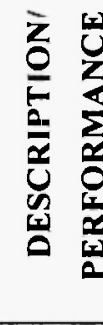 & 范 & \multicolumn{11}{|c|}{$\begin{array}{l}\text { Waspalloy is an age hardening nickel base alloy with useful strength at temperatures to } 760 \text { - } \\
871{ }^{\circ} \mathrm{C} \text {, and good oxidation resistance in gas turbine engine atmosphere upto } 871{ }^{\circ} \mathrm{C} \text {. The } \\
\text { creep rupture strength of Waspaloy is superior to that of RA718 at temperatures above } 621 \text { - } \\
649{ }^{\circ} \mathrm{C} \text {. Short time hot tensile strength is inferior to RA718 at temperature upto } 732{ }^{\circ} \mathrm{C} \text {. A } \\
\text { typical heat-treatment is solution treatment at } 1079^{\circ} \mathrm{C} \text {, } 4 \text { hours, air cool. Stabilize } 843{ }^{\circ} \mathrm{C}, 24 \\
\text { hours, air cool. Age } 760^{\circ} \mathrm{C}, 16 \text { hours, air cool. }\end{array}$} \\
\hline \multicolumn{3}{|c|}{ FEATURES: } & \multicolumn{10}{|c|}{ High strength, Oxidation resistance to $871^{\circ} \mathrm{C}$} \\
\hline \multicolumn{3}{|c|}{ APPLICATIONS: } & \multicolumn{10}{|c|}{ Gas turbine engine components, Shafts, Fasteners } \\
\hline \multicolumn{13}{|c|}{ Chemical composition range $(\%)$ : Balance Nickel } \\
\hline $\mathrm{Cr}$ & Mo & $\mathrm{Co}$ & $\mathrm{Al}$ & $\mathrm{Ti}$ & \begin{tabular}{l|l|l} 
& $\mathrm{B}$ & \\
\end{tabular} & $\mathrm{C}$ & $\mathrm{Fe}$ & $\mathrm{Mn}$ & Si & $P$ & $\mathbf{S}$ & $\mathrm{Cu}$ \\
\hline $\begin{array}{l}\vec{N} \\
\infty\end{array}$ & $\stackrel{n}{r}$ & $\frac{n}{\grave{c}}$ & $\stackrel{\circ}{\grave{n}}$ & $\begin{array}{l}\tilde{n} \\
\stackrel{n}{n} \\
\stackrel{i}{i}\end{array}$ & $\begin{array}{l}\overline{0} \\
0 \\
\dot{1} \\
\grave{o} \\
0 \\
0\end{array}$ & $\begin{array}{l}\overline{0} \\
\stackrel{1}{0} \\
0\end{array}$ & 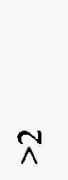 & $\vec{i}$ & $\frac{n}{\dot{\Lambda}}$ & $\stackrel{n}{\circ}$ & $\stackrel{n}{0}$ & $\vec{i}$ \\
\hline \multicolumn{9}{|c|}{$\begin{array}{l}\text { Mechanical/physical properties of heat-treated sheet } \\
\text { Density: } 8.192 * 10^{6} \mathrm{~kg} / \mathrm{mm}^{3} \text {, Melting range: } 1056-1384^{\circ} \mathrm{C} \text {. }\end{array}$} & \multicolumn{4}{|c|}{$\begin{array}{l}\text { Typical rupture strength of } \\
\text { heat-treated sheet }\end{array}$} \\
\hline \multirow[t]{2}{*}{ Temp. } & \multirow{2}{*}{\multicolumn{2}{|c|}{$\begin{array}{l}\text { UTS } \\
\text { (MPa) }\end{array}$}} & \multirow{2}{*}{\multicolumn{2}{|c|}{$\begin{array}{l}0.2 \% \mathrm{Y} \\
\mathrm{S} \\
(\mathrm{MPa})\end{array}$}} & \multirow[t]{2}{*}{$\begin{array}{l}\mathrm{E} / \% \quad \text { in } \\
51 \mathrm{~mm} \\
(\%)\end{array}$} & \multirow[t]{2}{*}{$\begin{array}{l}\text { Hardness } \\
\mathrm{R}_{C}\end{array}$} & \multirow{2}{*}{\multicolumn{2}{|c|}{$\begin{array}{l}\text { Mod. of } \\
\text { Elasticity, } \\
\text { Dynamic, } \\
\text { MPa } \times 10^{4}\end{array}$}} & \multirow[t]{2}{*}{$\begin{array}{l}\text { Temp. } \\
\left({ }^{\circ} \mathrm{C}\right)\end{array}$} & \multicolumn{3}{|c|}{$\begin{array}{ll}\text { Stress } \mathrm{MPa} & \text { to } \\
\text { rupture } & \text { at } \\
\text { indicated time } & \\
\end{array}$} \\
\hline & & & & & & & & & & \multicolumn{2}{|c|}{$100 \mathrm{hrs}$} & $\begin{array}{l}1000 \\
\text { hrs }\end{array}$ \\
\hline \multicolumn{2}{|l|}{21} & 1262 & \multicolumn{2}{|l|}{910} & 27 & $34-40$ & \multicolumn{2}{|l|}{--} & 649 & \multicolumn{2}{|c|}{643} & 552 \\
\hline \multicolumn{2}{|l|}{649} & 1193 & \multicolumn{2}{|l|}{772} & 21 & & \multicolumn{2}{|c|}{17.6} & 704 & \multicolumn{2}{|c|}{517} & 393 \\
\hline \multicolumn{2}{|l|}{760} & 965 & \multicolumn{2}{|l|}{772} & 12 & & 16.8 & & 760 & 43. & & 241 \\
\hline 871 & & 545 & 414 & & 12 & & 15.8 & & 816 & 22 & & 131 \\
\hline & & & & & & & & & 871 & 12 & & 68.3 \\
\hline
\end{tabular}


Table 4

Data of rolled alloys for flying and land based turbine market- The RAX[40].

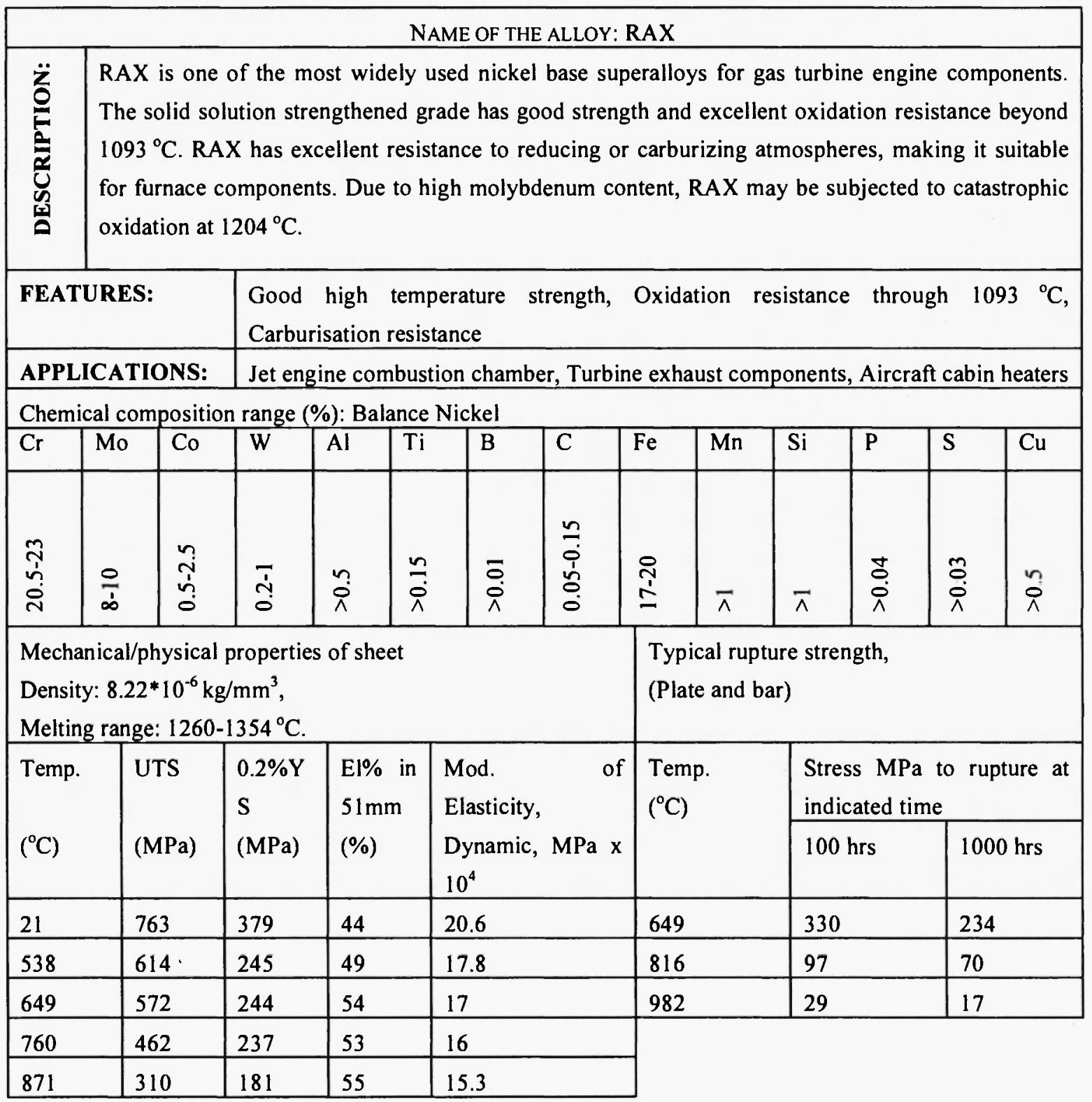

\section{FATIGUE IN GAS TURBINES}

The delay in introduction of novel advanced materials into aero gas turbine engine designs has led to a requirement to employ existing alloys at temperature and stress regimes beyond the limits for which they are 
originally employed as shown in Figure $3 / 41$. Consequently safety requirements of critical components such as discs operating in the high-pressure compressor and low-pressure turbines have dramatically increased. An understanding of crack nucleation and growth under cyclic loading is vital if in-service failures are to be avoided. Defect tolerant based techniques to estimate fatigue life by integrating fracture mechanics expressions from an initial flaw size to a crack size responsible for ultimate rapid failure of burst have been successfully employed. Such fracture mechanics approaches rely upon the accuracy of the crack growth models and require detailed characterization of crack growth rates obtained from laboratory test pieces under simple waveforms of constant amplitude. However, as the operating temperatures rise, such simple loading cycles may not be adequate to represent in-service damage resulting from creep-fatigue and oxidation mechanisms in particular. The influence of environment and waveform on the rate and form of fatigue crack growth in Inconel 718 at $600{ }^{\circ} \mathrm{C}$ has been investigated to determine the crack propagation lives of model discs that crack due to rim stress concentration. The crack growth was measured at a reduced pressure of approximately $150 \mathrm{~Pa}$ and compared with results obtained under atmospheric pressure and at high vacuum $142 \%$.

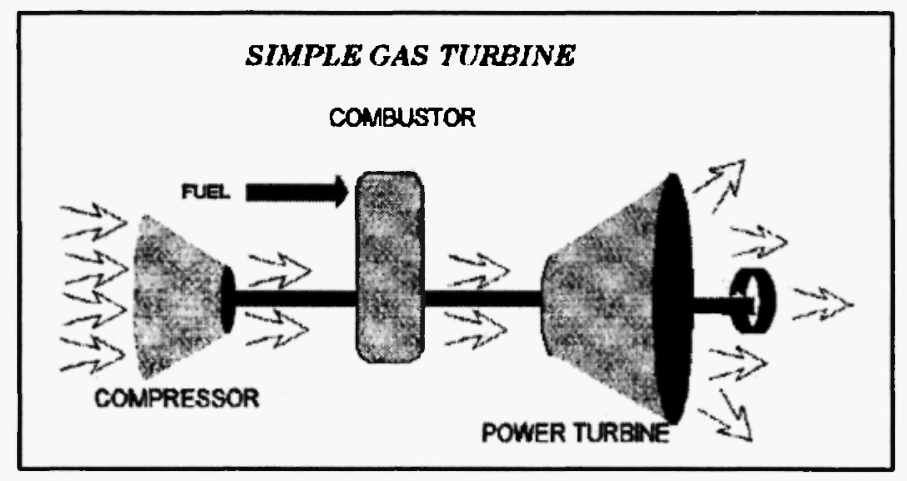

Fig. 3: Schematic of a gas turbine $/ 41$.

The variety of the alloying elements present in nickel base superalloys can be structured very well to improve creep-fatigue properties using sophisticated alloy design approaches. Besides the three classes of $\gamma$ stabilizing, $\gamma^{\prime}$ stabilizing, and grain boundary active elements, one can distinguish between the two subclasses of carbide forming and high temperature oxidation as well as high temperature corrosion protection elements. It is important to note that not only the strengthening microstructures inside the grains as well as on their boundaries are raising the creep and fatigue strength but at high temperatures the creep and fatigue strength are also determined by the grain geometry (grain aspect ratio).

The interaction between thermo mechanical fatigue and matrix oxidation in a cyclic thermo mechanical loaded IN $738 \mathrm{LC}$ superalloy at $400-900^{\circ} \mathrm{C}$ in air has been investigated. SEM images indicate general as well as preferential matrix oxidation of interdendritic and intergranular areas. Optical micrographs of 713LC 
before and after creep at $1000^{\circ} \mathrm{C}$ are shown in Figure 4. It is suggested that the mechanical strain range influences the general matrix oxidation and that the oxidation kinetics of a matrix under thermo mechanical fatigue is linear $/ 43 /$.

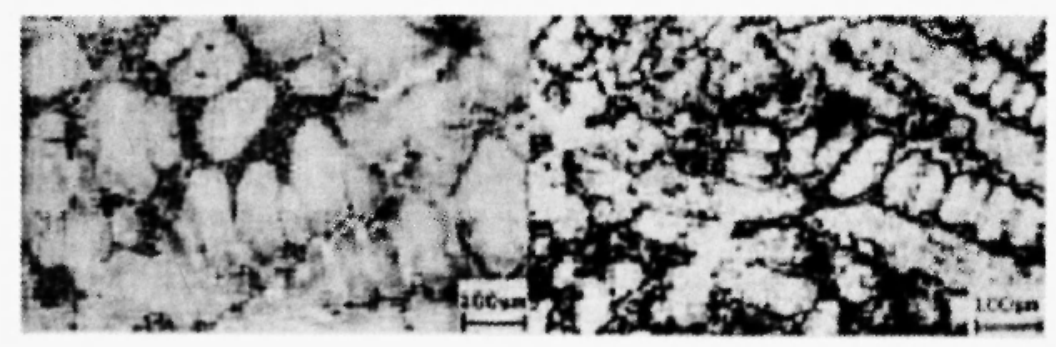

Fig. 4: Optical micrograph $(\times 100)$ of a $713 \mathrm{LC}$ alloy before (left) and after (right) a creep test at $1273 \mathrm{~K}$ for $\sim 50000$ hours $/ 23 /$.

The fatigue initiations and subsequent behavior of a (single) macrocrack in conventional, isotropic single crystal materials are significantly complicated. The effects of the cyclic period hold time and the stress intensity factor on the rates of fatigue growth in the temperature range $550-700{ }^{\circ} \mathrm{C}$ have been investigated for superalloys used in gas turbine engine disc applications, waspalloy and DAINCO 718. It is concluded that time dependent processes have significantly different influences in the fatigue crack growth rate, depending on the temperature, the crack period of the applied load cycle and the presence or absence of a hold time at maximum load. Present available models of predicting fatigue crack growth under complex loading histories in the gas turbine engine alloys appear to become inaccurate only at the highest temperature of operation and would probably be conservative, predicting a faster rate of crack growth than the service experience $144 /$. The inelastic deflections of industrial gas turbine combustion transition pieces as shown in Figures 5(a) and 5(b) have been analytically calculated using the finite element method in which start up and shut down cycling of pressure and thermal loading have been incorporated to obtain ratcheted deflections close to field measurements $145,46 /$. Bilinear kinematic hardening and a three constant power law represent plasticity and creep behavior of the nickel base superalloy Hastelloy-X. An incremental solution technique allows proper distribution of plastic strain due to loading and creep strain due to increasing time. Design engineers without a high level of finite element expertise and extremely large computer resources use the commercial finite element computer code ANSYS for new gas turbine development $/ 47 \%$. Fatigue cracks in plates of the combustor case of a gas turbine made of welded alloy Inconel 617(UNS NO 6617) and alloy Nimonic 75 (UNS NO 6075) initiate at the outer subsurface within the intergranularly cracked coarse grains adjacent to the weld and then propagate because of combustion vibration during start up operation conditions. To avoid such fracture, the proper welding procedures must be carefully considered to avoid introduction of high heat input during the welding process. A cold thermal cycle (low heat input) should be employed to reduce the 
coarsening of grains and precipitation in the grain boundaries. Vibration of the gas turbine chamber must be minimized so that the introduction of high stress concentrations in the chamber design, such as curvatures must be avoided /48/. Figures 6(a) and 6(b) show the intricacies of a coated combustor of RB211/49/ and a Mercury-50 design $/ 50 /$.

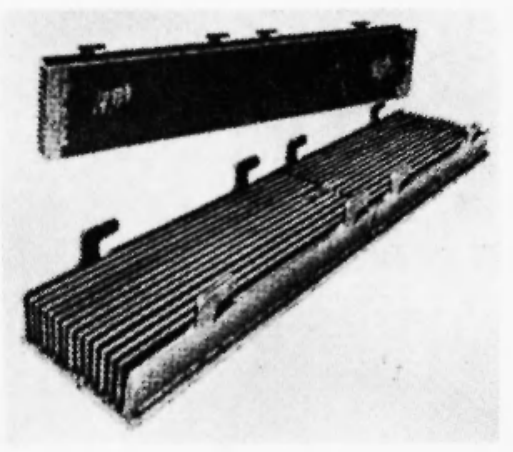

Fig. 5a: Combustor tile section of a huge industrial gas turbine $145 \%$

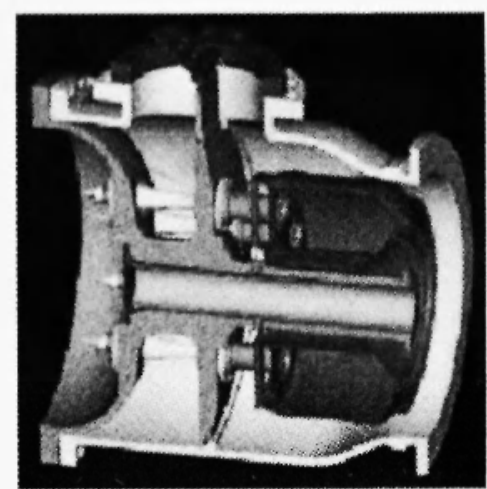

Fig. 6a: Thermal barrier coated RB combustor $/ 49 /$

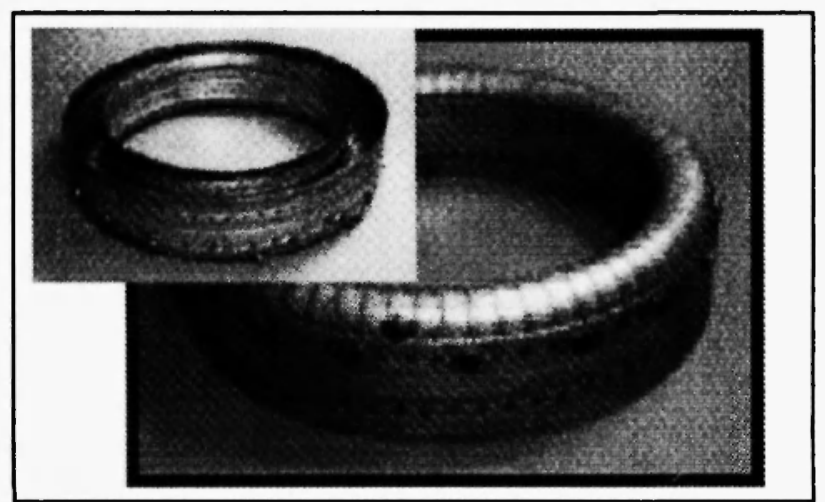

Fig. 5b: Hastelloy $X$ alloy and Haynes 188,230 , and 263 alloys are used for combustors, transition ducts, hot gas castings and exhaust housings for industrial gas turbines $/ 46 /$.

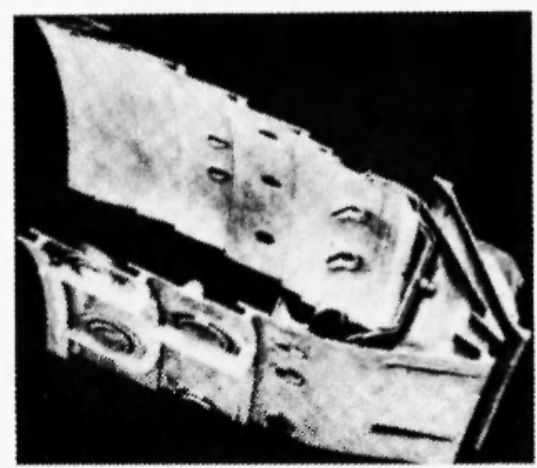

211 Fig. 6b: Mercury 50 combustion system $/ 50 /$.

Nickel base superalloys offer a unique balance of properties. They are well suited to meet the demands of the modern combustion turbine that are subjected to a complex combination of elevated temperatures, high stresses and an aggressive environment. These arduous operating conditions lead to creep, mechanical fatigue, thermo mechanical fatigue, and gaseous corrosion, which limit the service lives of components. 
Material degradation requires the periodic replacement of hot section components, which is a costly proposition. The high cost involved in replacing parts has provided a strong incentive for reconditioning components and for determining economic methods of extending their service lives. The timely application of an appropriate rejuvenation treatment has the potential to extend the useful life of a component significantly. However, the complex nature of the superalloys demands that each alloy must be considered individually with due regard to service history. A successful, rejuvenation treatment must be tailored to suit a particular alloy and be appropriate for the type and amount of damage accumulated. Much has been published on the rejuvenation of nickel base superalloys in which heat treatments are usually performed at temperatures above the $\gamma^{\prime}$ solvus temperature to develop a microstructure closely resembling that of the alloy before service exposure. Sub-solvus rejuvenation heat treatments may be successfully applied to less complex alloys. These treatments effectively sinter small cavities. However, once creep cavities grow beyond a certain critical size they cannot be sintered by heat treatment alone. The application of hipping can repair physical damage such as internal cracks and voids $151,52 \%$ Thermal fatigue cycling in turbine blades under laboratory conditions has been used at Rolls Royce since 1955. Fatigue results show good agreement with those observed during engine service $/ 53,54$.

\section{FATIGUE OF THERMAL BARRIER COATED SYSTEMS}

Deformation mechanism in TBCs for a diesel engine through rig tests, structural analysis modeling, and non-destructive evaluation has been studied. The knowledge has been utilized to develop improved TBCs as shown in Figure 7, $141 \%$.

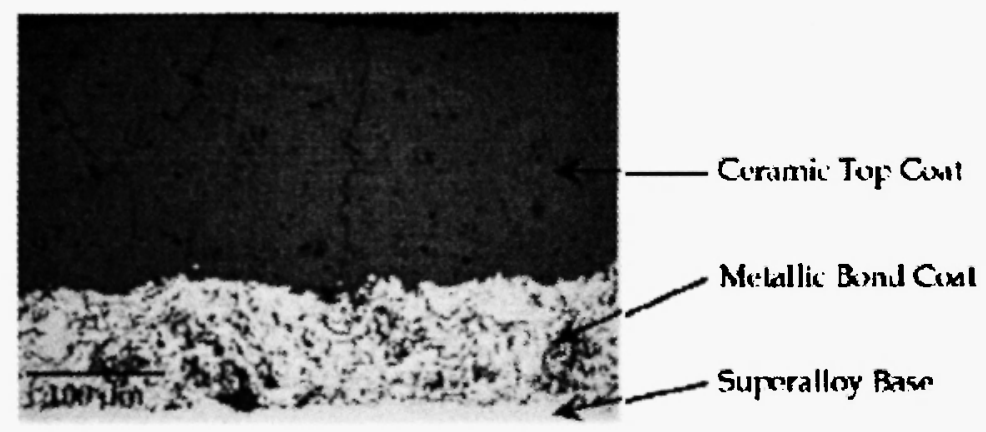

Fig. 7: Microstructure of a thermal barrier coating (TBC) system /41/.

The impact of TBCs on engine performance and fuel consumption has not been well established. Changes in fuel consumption appear to be less than a few percent and can be negative for state of the art diesel engines. The ability of the TBC to improve fuel economy depends on a number of factors, including the fuel 
injection system, combustion chamber design, and initial engine fuel economy. Limited investigation on state-of-the-art diesel engines have indicated that surface connected porosity and coating surface roughness may influence engine fuel economy. Current research on TBCs is primarily directed at the reduction of in cylinder heat rejection, thermal fatigue protection of underlying metal surfaces and possible reduction of diesel engine emission. Significant developments are still required to improve the plasma spray processing capability and the economics for complex geometry diesel engine components $/ 55 /$. Recent work has demonstrated that the thermal fatigue life of TBC, plasma sprayed with sol-gel processed zirconia $7 \mathrm{wt}$. \% yttria increases by a factor of five when the silica content is reduced from 1.0 to $0.1 \%$. The increase in life does not appear to be related to any observable differences in microstructure as a function of silica content. It is speculated that the change in life is due to differences in sintering or time dependent deformation of the coatings during thermal exposure. The sintering rates have been examined for coatings containing 0.1 and $1 \%$ silica. The measurements indicate an increase in sintering with increasing silica content. Sintering of thermal barrier coatings has been related to an increase in the elastic modulus and strength of plasma sprayed zirconia. Preliminary deformation studies suggest that the 0.1 and $1 \%$ silica coatings exhibit different dependence of deformation on the strain rate. The effect of the difference in deformation on TBC life is unclear, as the failure mechanisms during thermo mechanical fatigue are not well understood. Thermo mechanical fatigue (TMF) and isothermal fatigue (IF) experiments on bare MAR M246 and bare and coated MAR M247 nickel based superalloys at strain ranges from 0.335-1\%, in the temperature range of 500-1038 ${ }^{\circ} \mathrm{C}$ and at a constant strain rate of $5 \times 10^{-5} / \mathrm{sec}$ have been performed in air. Due to the coarse grained structure of MAR-246, TMF lifes are scattered considerably under low strain range conditions. Electron microscopy studies show that significant surface oxidation and $\gamma^{\prime}$ depleted zones occur in MAR M 246 under these conditions. In the surface grain, where the change in $\gamma^{\prime}$ morphology is most pronounced, $\gamma^{\prime}$ is rafted along axes approximately $\pm 45^{\circ}$ from the loading axis. The influence of a protective coating on the IF and TMF lifes of MAR-M247 have been examined. Results indicate that the coating does not significantly affect the fatigue lifes of MAR-M247. The oxidation behavior of bare and coated MAR-M247 has been investigated via X-Ray microprobe and Auger Spectroscopy. It is evident from the analysis that the coating is completely degraded when exposed to the test environment for a long time. In both the MAR-M246 and MAR-M247, in phase thermo mechanical fatigue (TMF) loading results in intergranular cracking. TMFIP loading promotes multiple cracks at the coating/substrate interface of coated MAR-M247. Eshelby techniques are used to calculate stress distributions in the vicinity of a surface oxide and second phase particles at the coating/substrate interface 156/. Material evolution, porosity control and other important parameters are needed to obtain high-level insulation but the easiest way is to increase the coating thickness. However, $\mathrm{TBCs}$ should possess high bond strength and good thermal fatigue resistance which are also affected by the coating thickness. NiCrAlY bond coat and $8 \mathrm{wt} \%$ yttria stabilized zirconia top coat with various thicknesses have been deposited by plasma spraying to investigate the effect of the thickness of the bond coat and top coat on the bond strength and thermal fatigue characteristics. Residual stresses of the top coat have been 
calculated by the finite element method (FEM) and the results used to explain the relationship between the techniques of the bond coat and top coat and bond strength and thermal fatigue characteristics. The results of FEM are confirmed by measuring the residual stress in the topcoat by X-Ray diffraction (XRD) /57/. TBC should achieve both a high level insulation and a low level of interfacial expansion mismatch stress. These criteria can be met by yttria-zirconia-zirconia with relatively low thermal conductivity and a high thermal expansion coefficient $/ 58$. The bond strength of TBCs increases with decreasing maximum residual stress in the $y$-direction of the topcoat. The thermal fatigue characteristics increase with decreasing maximum residual stress in the Y-direction of the topcoat. The thermal fatigue characteristics increase with decrease in the maximum principal residual stress of the topcoat and oxidation thickness layer of the bond coat. Lowest creep resistant bond coat leads to overall failure. Interfacial stresses relieved within few seconds by bond coat creep at elevated temperature. Strain initiation of the bond coat on aging and oxidation depends on loss of plasticity and a stress increase for thermal cycle respectively. Lower the durability of the ceramic coating. Rapid spallation results in mechanical deformation or compression. Thickness cracking appears on samples by substrate or mechanical cycling of fatigue. During thermal cycling the difference in thermal conductivity reduces the substrate and bond coat temperatures faster as compared to ceramic coats during the cooling step. Mechanisms of the bond coat deformation are described by strain isolation of the bond coat at high temperatures. Bond coat deformation, compressive stress, and partially oxidized bond coat which originate from thermal cycling affect the life of coating. Delamination of the ceramic coating which arises from the stress concentration at a flaw or defect at the interface raises the temperature and fails with the explosive force during heat cycling. Surface roughness on the bond coat improves adhesion through mechanical keying and diffusion. Since the initiation of delamination is always in the cohesive zone and in the ceramic layers as well as adjacent the interface, the geometry of stress transmission across the interface is more important in affecting durability than the adhesion zone alterations $158 /$. Most recent work on the characterization of rupture and fatigue resistance of TBC superalloy deals with the high - temperature, high-cycle fatigue and accelerated creep properties of thermal barrier coated Superni C263 alloy used as a candidate material in combustor liners of aero engines /59/. An acoustic emission technique has been utilized to detect the ductilebrittle transition temperature of the bond coat. Results revealed that the DBTT (ductile - to - brittle transition temperature) of this bond coat is around $650^{\circ} \mathrm{C}$, which is in close proximity to the value reported for CoCrAlY type of bond coat. The endurance limit in high temperature load controlled fatigue and the life of TBC coated composite under accelerated creep conditions are substantially higher than those of the substrate material (see Figure 8) because oxidation is likely the cause of the reduced life times of the bare substrate as compared to the coated substrate 159,60 . Fractographic features at high stresses under fatigue were intergranular cleavage whereas those at low stresses were transgranular and ductile in nature. Delamination of the bond coat and spallation of the TBC at high stresses during fatigue were evident. The finite element technique used for analysing the equivalent stresses in the bond coat well within the elastic limit, revealed the highest order of equivalent stress at $800^{\circ} \mathrm{C}$ as the bond coat is ductile above $650^{\circ} \mathrm{C} / 60 /$. 


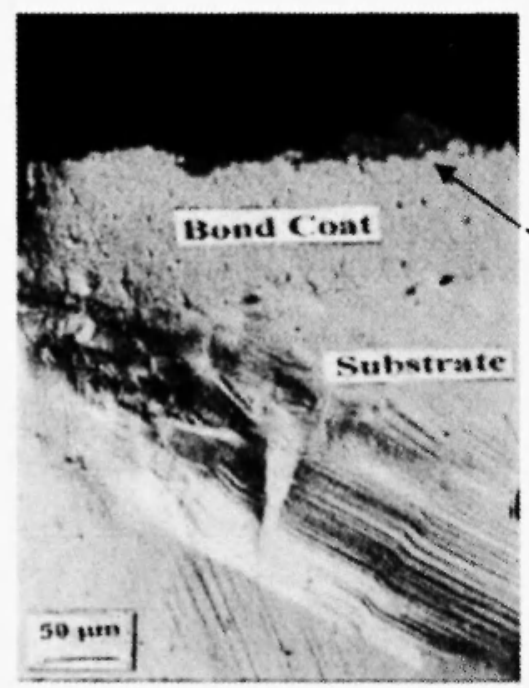

Spallation of TBC

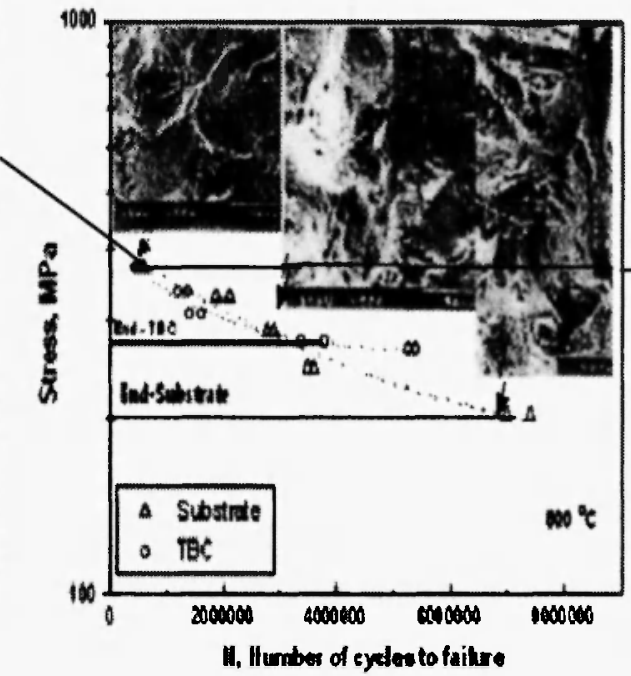

II, llumber of eyderto faiture

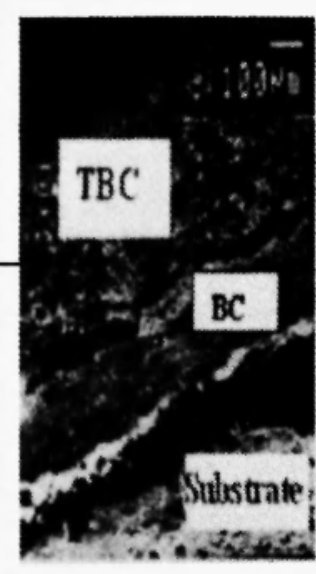

Delamination of TBC and bond coat

Fig. 8: Plot of elastic stress range versus number of cycles to rupture for the substrate (Superni C263 alloy) and TBC at $800^{\circ} \mathrm{C} / 59 /$. SEM fractograph of a ruptured specimen (on the left) which failed at $90 \% \mathrm{YS}$ ( $370 \mathrm{MPa}$ ) in force- controlled high temperature fatigue tests, revealing spallation of the TBC layer.

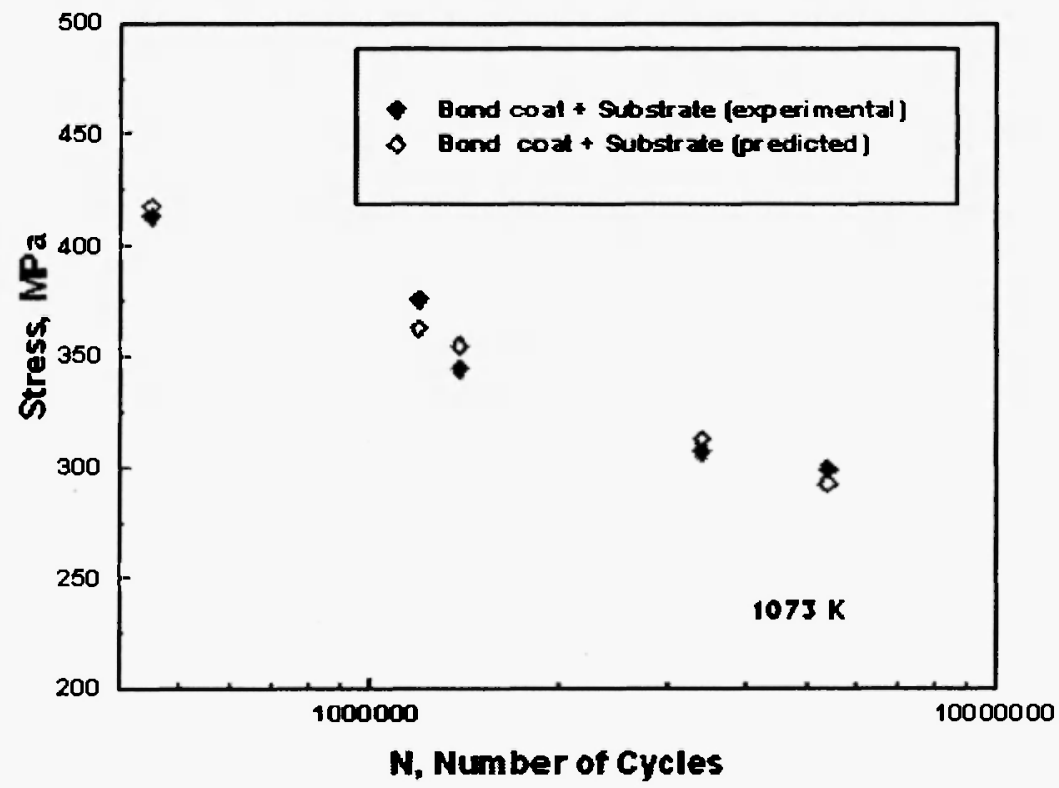

Fig. 9: Variation of elastic fatigue stress range with number of cycles to rupture at $800^{\circ} \mathrm{C}$, for the bond coat + substrate (experimental and predicted) $/ 60 \%$. 


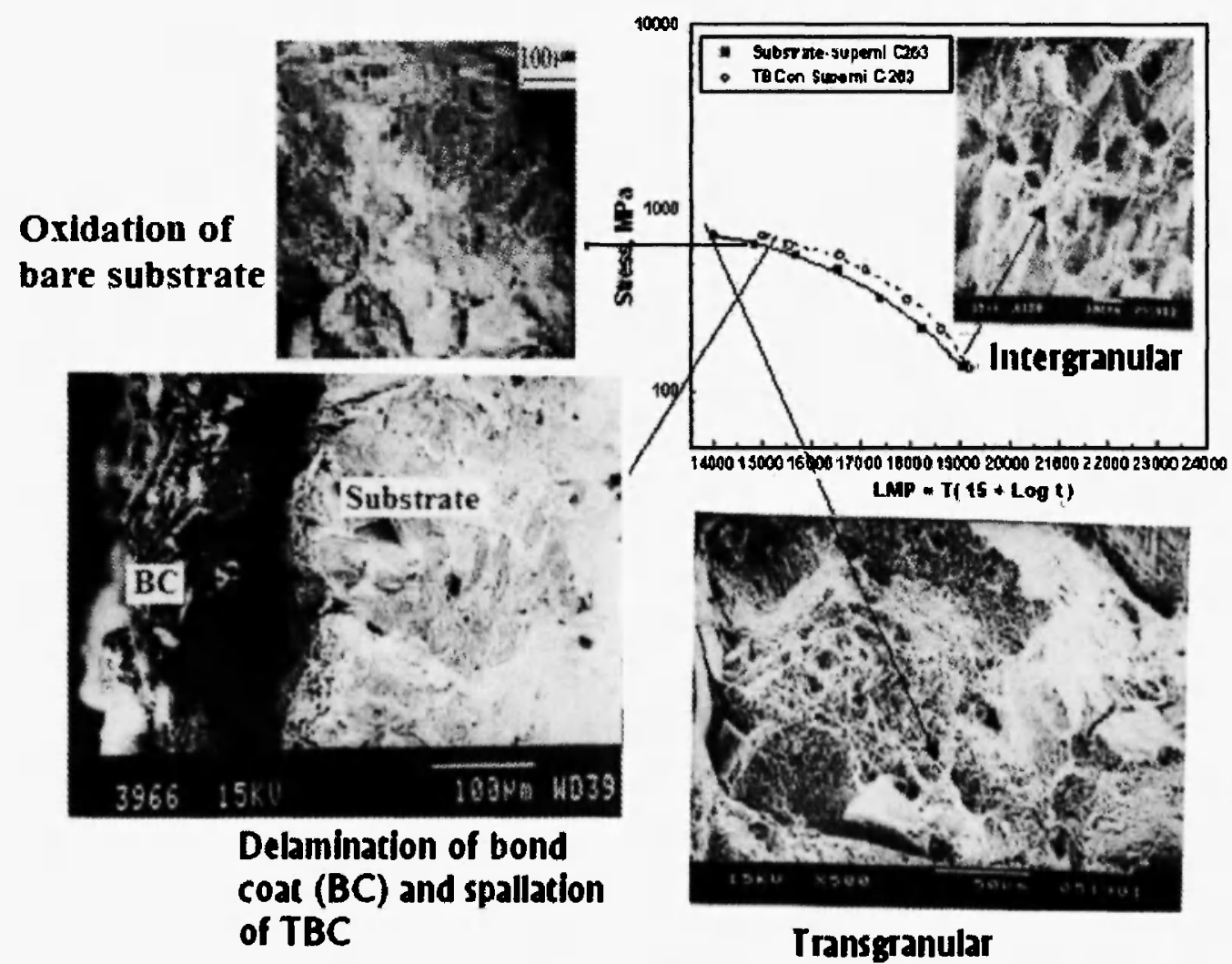

Fig. 10: Variation of stress with LMP (Larson Miller Parameter) for the substrate (Superni C 263 alloy) and for TBC /60].

The comparison of the fatigue properties of the substrate + bond coat (experimental) and the substrate + bond coat (predicted) is shown in Figure $9 / 60 \%$. It was also observed that the predicted as well as the experimental fatigue stress data for the bond coat + substrate are in close proximity. Unlike in the case of fatigue, the mode of fracture in the substrate at very high stresses was transgranular whereas that at low stresses was intergranular in creep, as shown in Figure $10 / 60 /$. It was evident that the substrate had negligible estimated rupture strength after 1000 hours of service exposure. Therefore, the substrate should be such that it should have a favourable creep rupture strength at and above $800{ }^{\circ} \mathrm{C}$ after $1000 \mathrm{hrs}$ of service exposure. It was finally recommended that these TBCs should not be put into use above $800^{\circ} \mathrm{C}$ for more than 1000 hours of continuous operation as the strength of the TBC superalloy drops to negligible levels $/ 59 /$.

Effects of corrosion resistance coating such as CoNiCrAlY and Al chemical vapour deposition (CVD) coating on the fatigue creep interaction life of a cast nickel base superalloy Rene- 80 have been studied. CoNiCrAlY coating leads to improved resistance to surface crack initiation while Al chemical vapour deposition (CVD) coating reduces the number of cycles to surface crack initiation. However, the surface 
crack propagation rate of both the coated and uncoated specimens remains unaffected. Under creep-fatigue interaction conditions, the numbers of cycles to surface crack initiation of the coated specimen increase in comparison with the uncoated specimen. It is evident that the oxidation of the specimen surface and the properties of the coating material affect the fatigue life of the coated specimen. The life under fatigue-creep interaction is also affected to a great extent by the failure mechanism (intergranular cracking) of the base metal Rene $80 / 61 \%$. The thermal cycling resistance of TBCs on Hastelloy-X has been investigated, with $\mathrm{Ni}-22 \mathrm{Cr}-$ $10 \mathrm{Al}-1 \mathrm{Y}$ as the bond coat and $\mathrm{ZrO}_{2}-8 \mathrm{wt} \% \mathrm{Y}_{2} \mathrm{O}_{3}, \mathrm{ZrO}_{2}-13 \mathrm{wt} \% \mathrm{Y}_{2} \mathrm{O}_{3}$, and $\mathrm{ZrO}_{2}-20 \mathrm{wt} \% \mathrm{Y}_{2} \mathrm{O}_{3}$ respectively, as the topcoat. The duplex and graded thermal barrier coatings are applied by using air plasma spray (APS). After thermal cyclic testing the results show that tetragonal $\mathrm{ZrO}_{2}-8 \mathrm{wt} \% \mathrm{Y}_{2} \mathrm{O}_{3} / \mathrm{Ni}-22 \mathrm{Cr}-10 \mathrm{Al}-1 \mathrm{Y}$ duplex TBC exhibits the best thermal cyclic life. Cubic microstructure which appears in the $\mathrm{ZrO}_{2}-20 \mathrm{wt} \% \mathrm{Y}_{2} \mathrm{O}_{3}$ TBC is degraded by the thermal induced stresses. But the graded coating increases the life of the thermal cycle of $\mathrm{ZrO}_{2}-20 \mathrm{wt} \% \mathrm{Y}_{2} \mathrm{O}_{3}$ TBC /62/. The effect of plasma-sprayed thermal barrier coatings made up of a single layer $\mathrm{ZrO}_{2}$ (stabilized with $8 \mathrm{wt} \% \mathrm{Y}_{2} \mathrm{O}_{3}$ ), and functionally graded materials ( $\mathrm{FGMs}$ ) consisting of multilayers with varying mixture ratios of $\mathrm{ZrO}_{2}$ coatings on Ni-base superalloys have been studied. The functionally gradient materials comprise different material components such as ceramics and metals with a continuously varying mixture ratio and microstructure in order to relax the thermal stress due to high temperature gradients. They are recent developments. FGM mitigates thermally induced stresses in the coating thereby improving its life. In order to evaluate the stress state of coatings induced by laser heating during thermal shock tests and to discuss the fracture process, numerical computations of transient thermal stresses are performed using the finite element method. It helps to determine the thermal characteristics of the coating in terms of the critical laser power density. It is shown that the critical power density of the FGMs is significantly higher than that of the single layer coating, indicating the effectiveness of the FGMs to reduce the thermal expansion mismatch stress $/ 63 /$. A method has been developed to determine the performance of FGMs related to thermal resistance and thermal fatigue. In this experiment high temperature gradient conditions are accomplished by heating one side of a specimen with a Xenon lamp while cooling the other surface with liquid hydrogen or nitrogen in vacuum. The evaluation of the samples consists of the metallographic examination and measurement of the variation of the effective thermal conductivity with respect to the delaminating damage and subcritical cracks. Some $\mathrm{ZrO}_{2} / \mathrm{NiCoCrAIY}$ samples fabricated by several methods are examined under several sets of conditions. It is evident that FGMs are quite promising for decreasing the thermal stresses under high heat loads $/ 63,64 /$.

The constitutive (load-strain) relations of thermal barrier coatings of plasma-sprayed $\mathrm{ZrO}_{2}-8 \mathrm{wt} \% \mathrm{Y}_{2} \mathrm{O}_{3}$ have been determined in both ring-on-ring biaxial flexure and trans-thickness tension at ambient temperature. The method exhibits a non-linearity and hysteresis in the load-strain curves. The degree of non-linearity appears to be less in trans-thickness tension than in biaxial flexure. The corresponding constitutive load-strain relation remains almost insensitive, independent on the type of loading, both to the number of loading and unloading cycles and the test rate. The fracture strength is found to be much lower in trans-thickness tension than in biaxial flexure. It may be attributed to the materials unique layered structure produced by plasma spray $/ 65 /$. A study of 
residual stresses in $\mathrm{ZrO}_{2}-7 \mathrm{wt} \% \mathrm{Y}_{2} \mathrm{O}_{3}$ thermal barrier coating after spraying and thermal stresses during thermal shock testing show that stresses in the ceramic coatings influence the thermal shock resistance. Moreover the analysis demonstrates that the thermal shock resistance increases by controlling the residual stresses, stress relaxation and lowering the stress gradient at the interface of the coating substrate $166 /$. Thick thermal barrier coatings with layer graded bond coat systems have been developed for diesel engine applications. The concept of low expansion and layer-graded bond coat systems has been utilized for the novel systems which meet the stringent performance requirements under severe cyclic loading during engine operation. Thermal fatigue behavior of several coating systems has been evaluated using burner rigs and high heat flux laser tests under thermal transients which simulate those in diesel engines. Studies of the thermal-mechanical loading interfacial temperature and coating configuration on thermal barrier coating life indicate that the layer-graded bond coat system possesses lower interfacial stresses and excellent oxidation resistance as compared to conventional thick TBC coating systems there by improving the coating performance and durability significantly $167 /$.

A thick thermal barrier coating of $1.5 \mathrm{~mm}$ in thickness has been produced by plasma sprayed yttria partially stabilized zirconia. It contains a major phase of non-transformable tetragonal in as sprayed/laser-glazed conditions. This phase remains undecomposed even after several thousand thermal cycles between natural gas flame $\left(\sim 1000^{\circ} \mathrm{C}\right)$ and cold water quenching. The thermal cycling lifetime of a vacuum plasma spray bond coated TBC shows significant improvement in the durability laser glazing. The thermal cycling lifetime of the laser glazed TTBC increases by $\sim 40 \%$ over the untreated coating $/ 68$. Contrary to the thick thermal barrier coating approach used in insulated diesel engines, investigations have been carried out on the merits of thin coatings. Transient heat transfer analysis indicates that the temperature swings experienced at the combustion chamber surfaces depend primarily on material thermophysical properties, i.e. conductivity, density, and specific heat. Thus cyclic temperatures swings remain alike whether thick or thin $(<0.25 \mathrm{~mm}$ minimum) coatings are applied. Furthermore, thin coatings lead to lower mean component temperatures. It is also easier to apply this coatings than thick coatings. The thinly coated engine concept leads to modest improvements in brake power, lower exhaust emission, and higher exhaust temperatures for possible exhaust gas utilization. Other gains include improved piston-liner tribological behavior, improved erosion-corrosion resistance, and thus greater component durability. Above all, thin coatings may find application in the large gasoline engine market $169 /$.

A remarkable effect of the deposition temperature on thermal fatigue resistance in plasma spray thermal barrier coatings consisting of a NiCoCrAlY type bonding layer and a $\mathrm{ZrO}_{2}-0.25 \mathrm{CeO}_{2}-2.5 \mathrm{Y}_{2} \mathrm{O}_{3}$ topcoat on a nickel base superalloy has been reported. It is correlated with microcracking and internal stress distribution in a systematic manner $/ 70 /$.

TBC degradation is a phenomenon during useful lifetime. Table 5 shows the common type and causes of degradation on exposure to inflame and oscillate augmentation of gases in the hot section of gas turbines. The co-ordination and integration of life assessment methodologies have been collated in Figure 11, $/ 71$. 
Table 5

Common types and causes behind failure of thermal barrier coatings

\begin{tabular}{|c|c|c|c|c|c|}
\hline \multicolumn{6}{|c|}{ Thermal barrier coating (TBC) life limitations } \\
\hline Types & Causes & & Types & Causes & \\
\hline Erosion & & $\begin{array}{l}\text { Grit and dust } \\
\text { Flame turbulence }\end{array}$ & Sintering & ० & $\begin{array}{l}\text { Phase transformation of } \\
\text { TBC } \\
\text { Low temperature eutectic } \\
\text { formers }\end{array}$ \\
\hline Corrosion & $\begin{array}{l}0 \\
0\end{array}$ & $\begin{array}{l}\text { Fuel } \\
\text { Ambient atmosphere }\end{array}$ & Spallation & $\begin{array}{l}0 \\
0\end{array}$ & $\begin{array}{l}\text { Contaminant diffusion } \\
\text { Thermal shock }\end{array}$ \\
\hline Porosity & ० & $\begin{array}{l}\text { Interfacial } \\
\text { phenomenon } \\
\text { Elemental depletion } \\
\text { of bond coat }\end{array}$ & $\begin{array}{l}\text { Metal fatigue } \\
\text { (Airways sector) }\end{array}$ & & $\begin{array}{l}\text { Thermal } \\
\text { Thermomechanical }\end{array}$ \\
\hline Delamination & & $\begin{array}{l}\text { TGO growth } \\
\text { Edge effect }\end{array}$ & $\begin{array}{l}\text { Metal creep } \\
\text { (Industrial } \\
\text { sector) }\end{array}$ & $\begin{array}{l}\circ \\
\circ\end{array}$ & $\begin{array}{l}\text { Duration of exposure } \\
\text { Creep rate }\end{array}$ \\
\hline
\end{tabular}

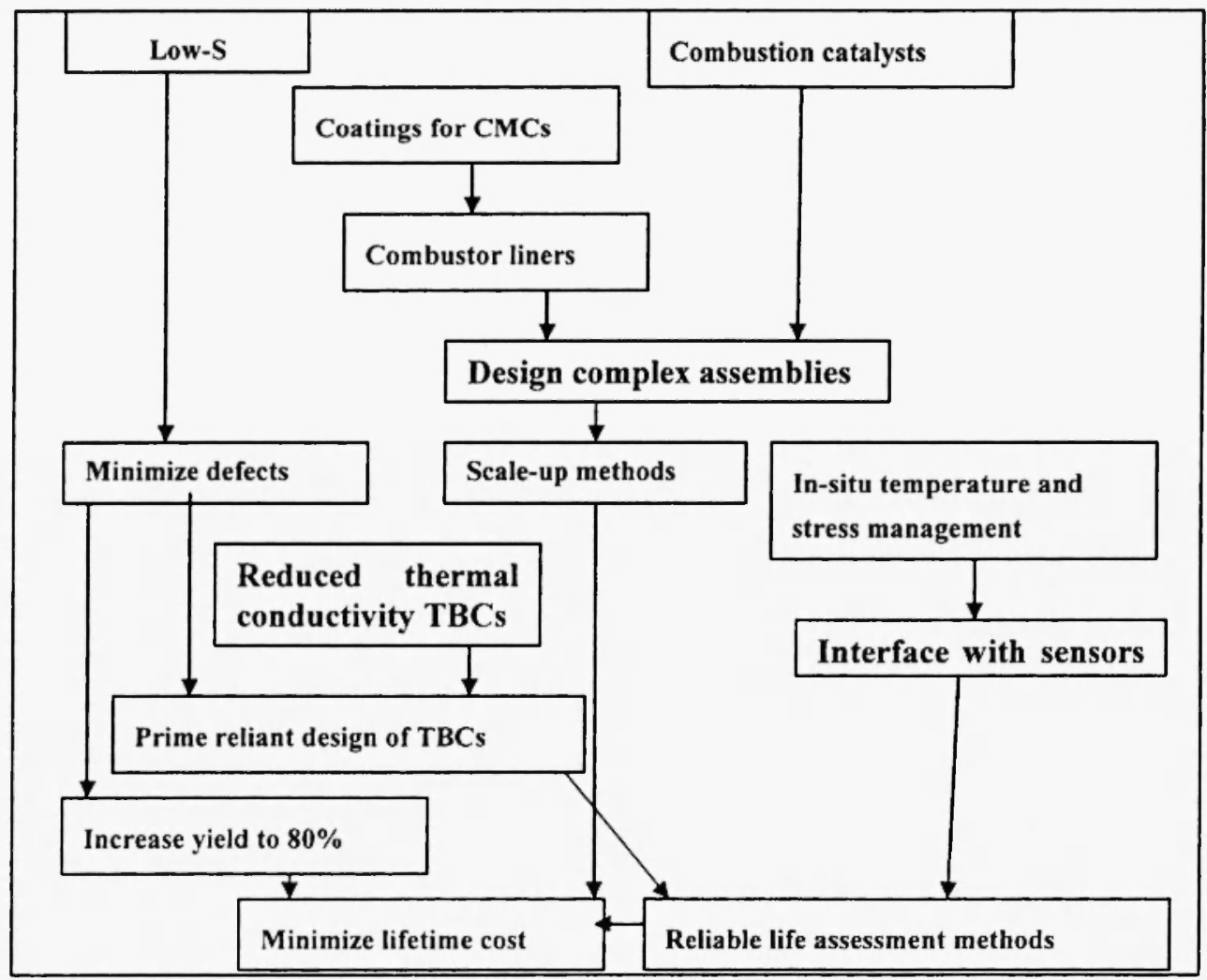

Fig. 11: Co-ordination and integration of life assessment methodologies /71]. 


\section{CONCLUSIONS}

Fatigue in gas turbine hot section implements are controlled by a creep-fatigue-oxidation mechanism by varying the composition of the aggressive environment. Differences in experimented evaluations and service exposed evaluations arise as a result of abnormal consequences of implementation, deficiency related to high empiricism and lack of inclusion of proper variables to the experimented formulation. Thermal barrier coated substrates suffer from failures related to bond coat creep, fatigue, and oxidation. The life limiting variables are mostly stress and composition variation/depletion in origin. The substrate should be such that it should have a favourable creep rupture strength at and above $800{ }^{\circ} \mathrm{C}$ after $1000 \mathrm{hrs}$ of service exposure. The degradation is highly sensitive to temperature fluctuations above $800{ }^{\circ} \mathrm{C}$. The endurance limit in high temperature load controlled fatigue and the life of TBC coated composites under accelerated creep conditions are substantially higher than those of the substrate material because oxidation is likely the cause of the reduced life times of the bare substrate as compared to the coated substrate. The thermal fatigue characteristics increase with decrease of the maximum principal residual stress of the topcoat and the thickness of the oxidation layer of the bond coat. FGM mitigates thermally induced stresses in the coating, which in turn improves its life and durability in a dramatic manner. Use of FGM may be treated as a breakthrough in the area of TBCs.

\section{REFERENCES}

1. Z.A Chaudhury, G.M Newaz, S.C Nusier, T. Ahmed and R.L. Thomas, J. of Mater. Sci, 34, 2475 (1999).

2. F.R. Shklyer, G.L. Feigin and E.L. Surgucheva, Chernaya Metall, 12,118 (1987).

3. R. Panat, S. Zhang and K. J. Hsia, Acta Met. Mater, 51(1), 239 (2003).

4. Y.H. Zhang, P.J.Withers, M.D. Fox, D. M. Knowles, Mater. Sci. \& Technol, 15, 1031 ( 1999).

5. J.L. Smialek, Metall. Trans, 18A, 164 (1987).

6. G.E. Dieter, Mechanical Metallurgy $3^{\text {rd }}$ Ed, 1987; p. 375.

7. P.G. Forrest (Ed.), Fatigue of Metals, 1962, p. 238.

8. T. M. Yennshonis, J. of Thermal Spray Technology, 6(1), 50 (1997).

9. J.G. Goodjen, W.J. Brindloy and R.A. Miller, Proc. 8ih National Thermal Spray Conf., Houston, TX (15 $5^{\text {th }}$ Sept. 1995), p. 73.

10. M. Okazaki and Y. Yamazaki, Int. J. of Fatigue, 21, S79 (1999).

11. A.D. Boyd-Lee, Int. J. of Fatigue, 21, 393 (1999).

12. R.J.H. Wanhill, Int. J. of Fatigue, 24, 545 (2002).

13. H. Anderson, C. Persson and T. Hansson, Int. J. of Fatigue, 23, 81 7(2001).

14. A. Diboine, J.M. Paltier and R.M. Pelloux, High Temperature Fracture Mechanisms and Mechanics 
[Proc. Conf.], Dourdan, France, Mech. Eng. Pub., Northgate Avenue, Bury St Edmunds, Suffolk, IP326BW, UK, (1990) 421.

15. J.C. Hearly, L. Grabowski and C.J. Beevers, Int. J. of Fatigue ,13(2), 133 (1991).

16. D.N. Wang, X. Wang and Q.P. Kong, Academia Sinica. Mater. Sci. Eng. A ,142(2), 157 (1991).

17. J.C. Hearly, C.J. Bcevers and L. Grabowski, Monitoring fatigue of a nickel base superalloy at positive and negative stress ratios using an optical system, Fatigue Frac. Eng. Mater. Struct., 15, 3 (1992).

18. D.L. McDowell, S.D.Autolovich and R.L.T. Oahmke, Nucl. Eng. Des. 133(3), 383-399. (1992).

19. J. Lu and L.F. Flavenot, Failure Analysis Theory and Practice [Proc. Conf.] (19-24 ${ }^{\text {th }}$ Sept, 1988), Vol. 1, Budapest, Hungary, Engg. Materials Advisory Services Ltd., 339 Halesowen Rd., Cradly Health, Warley, West Midlands B646PH, UK (1988).

20. R. Dauzer, Creep, Characterization, Damage and Life Assessment [Proc.Conf.], Lake Buena Vista, Florida, USA, (18-21 May), ASM Int., Mater. Park, Ohio 44073-0002, USA, (Met. A, 9211-72-0495), (1992) 359.

21. N.M. Abnelfoutouh, Advances in Fatigue Life Time Predictive Techniques [Proc. Conf.], San Francisco, California, USA, (24 ${ }^{\text {th }}$ April) ASTM, 1916 Race St., Philadelphia, Pennsylvania 19103, USA, STP 1122, (Met. A, 9205-72-0222), (1992) 77.

22. N. Matsuda, S. Umezawa and J.Hitachi, J. Soc. Mater. Sci. 39(439), 419 (1990).

23. R Couturier and C. Escaravage, High temperature alloys for RTGR gas turbine: Required properties and development needs, CEREM, CEA-Grenoble, France, FRAMATOMENOVATOME, Lyon France.

24. Z.Mu and V.Z. Gerold, Metallkd, 82(8), 633 (1991).

25. H. Su, and J. He, Mater. Mech. Eng, 13(4), 30 (1989).

26. J.Byrne, N.Y.K. Kan, J.W.Hussey and G.F. Harrison, Int. J. of Fatigue 21, 195 (1999).

27. Vasisht Venkatesh and H.J. Rack, Int. J. of Fatigue, 21, 225(1999).

28. D.N. Mavris and B. Roth, $35^{\text {th }}$ Aerospace Sciences Meeting and Exhibition,(6-9 Jan.), Florida, USA, (1997).

29. I. Tusuji and K. Okada, J. Iron Steel Inst., Jpn., 77(4), 574 (1991).

30. A.D. Cetel and D.N. Duhl, Metals Abs, 25, 460078 (1992).

31. M.F. Henry, Patent No. US 5129968 (USA), Convention date ( $28^{\text {th }}$ Sept.) 1988.

32. M.F. Henry, Patent No. US 5130086 (USA), Convention date ( $1^{\text {st }}$ Aug.) 1990.

33. M.F. Henry,Patent No. US 5130087 (USA), Convention date (30 $0^{\text {th }}$ July) 1990.

34. M.F. Henry, Patent No. US 5130088 (USA), Convention date ( $13^{\text {th }}$ Aug.) 1990.

35. M.F. Henry, Patent No. US 5130089 (USA), Convention date ( $15^{\text {th }}$ Aug.) 1990.

36. R.G. Suider, Patent No. GB 2252563, Convention dates ( $7^{\text {th }}$ Feb.) 1991.

37. M.F. Henry, AUSZ. EUR. Patentanmeld (June) 1990, 6(24), 3472, Patent No. EP 0372170, Convention date (23 ${ }^{\text {rd }}$ Aug.) 1989.

38. M.F. Henry, (General Electric, AUSZ). Eur. Patentanmeld (June) 1990, 6(23), 3313, Patent No. EP 0371208 (European Patent), Convention date (23 ${ }^{\text {rd }}$ Aug.) 1989. 
39. E.A. Loria, JOM , 44(6), 33 (1992).

40. Rolled Alloys International Limited, 14, The Oaks Clems Road, Radditch, Worcestershire, B987ST, United Kingdom, Bulletin 152, Rolled Alloys. Inc, 3po3.5M, (2000).

41. Massimo Tommasi and Antonio Licciulli, Scienza e Technologia die Materiali Ceramici, A.A. 02 (2001).

42. L.J. Chen, Z.G.Wang, G. Yao and J.F. Tian, Int. J. Fatigue, 21(7), 25 (1999).

43. S. Esmacih, C.C. Engler Pinto Jr., B. Ilschner and F. Rezai-Aria, Scripta Metall. Mater, 32(11), 1777 (1995).

44. D.P. Deluca and C. Annis, Gov. Res. Announce. Index, AD-A248190/1/XAB,(1992) 45. W.J. Wicks, T.C. Radtke, Defence Science and Technol. Org. Australia, Australian Fracture Group, (Met.A, 9111 72-0515), (1990) 81.

45. W. Endres, P.R. Sahm and M.O. Speidel, High-temperature Materials in Gas Turbines, 1, Haynes International (England). Ltd., P.O. Box 10, Parkhouse Street, Openshaw, Manchester, M11 2ER, 1974; p. 1.

46. J.E. Barnes, Characterization, Damage, and Life Assessment, [Proc. Conf.], Lake Buena Vista, Florida, USA, (18-21 May) ASM Int., Materials Park, Ohio 4473-0002, USA, (Met. A, 9211-72-0495), (1992) 195.

47. Elshawesh., Elhond, T. Elmendelsi and A. Elware, Materials Performance, 36(7), 62 (1997).

48. G.W. Meetham, Mater. Sci. and Technol, 2, 290 (1986).

49. D.W. Esbeck, I.S. Gates and P.H. Schneider, (Research sponsored by U.S. Dept. of Energy's Morgantown energy technology center and Chicago operations office with solar turbines, Sandiago) 1997.

50. A. James, Mater. Sci. and Technol., 17. 481 (2001).

51. J.L. Pierce, L.P. Zawada and R.J. Srinivasan, J. of Mater. Sci, 35(12), 2973 (2000).

52. M.H. Coney, High Temp. Technol., 8(2), 115 (1990).

53. M. Lam, Failure Analysis: Techniques and Applications [Proc. Conf.], Montreal, Quelec, Canada, (8-11 July) ASM Int. Mater. Park, Ohio 44073-0002, USA, (1992) 137.

54. R.H. Hoel and I. Kvernes, Thermal Spray Advances in Coatings Technology, Conf. Proc., Ed. David L. Houck, ASM International, (1988) 291.

55. Y. Kadioglu and H. Schitoglu, J. Eng. Mater. Tech., (Trans. ASME), (1990) 94.

56. H.M. Choi, B.S. Kang, W.K. Choi, D.G. Choi, S.K. Choi, J.M. Kim, Y.K. Park and G.M. Kim, J. of Mater. Sci. 33, 5895 (1998).

57. A. Bennett, Mater. Sci. \& Technol, 2, 257 (1986).

58. A.K. Ray, D.K. Das, B. Venkataraman, P.K.Roy, B. Goswami, N. Roy, S.K. Das, , N. Parida, S. Tarafder, S.Chaudhuri and R. N. Ghosh, J Mater. Sci and Engg: A , 405, 194 (2005).

59. A.K Ray, E S. Dwarakadasa , N. Roy, B. Dash,. D.K. Das, B. Goswami, S.K. Sahay, D. Sanyal and R.N. Ghosh, High Temperature Materials and Processes, 25(3), 109 (2006). 
60. N. Matsuda, S. Umezawa and J. Hitachi, J. Soc. Mater. Sci., Jpn, 40,(449), 165.(1991).

61. L.T. Wu, C.S. Wu., C.C. Tzeng and W.L. Wang, Met. Ind. (China), (Suppl.), (1991) 78.

62. T. Hashida, H. Takahashi, K. Miyawaki,. J.Jpn. Soc., Powder Metall. 37(2), 307 (1990).

63. K. Kumakawa, M. Sasaki, S. Meada and N. Adachi, J. Jpn. Soc., Powder Metall. 37(2), 313 (1990).

64. S.R. Choi, D. Zhu and R.A. Miller, Ceram. Eng. Sci. Proc, 21(4), 653 (2000).

65. H.D. Steffens, Z. Babiak and U. Fischer, $2^{\text {nd }}$ Int. Conf. on Sutf. Eng. [Proc. Conf.], Stratford-uponAvon, UK, (16-18 June) The Welding Institute, Abington Hall, Abington, Cambridge CBI 6AI, UK, (1988) 471

66. R.A. Miller, D. Zhu., J.G. Goedjen, A.M. Colomino and T.A. Cruse, Ceram. Eng. Sci. Proc., 21(4), 635 (2000).

67. H. Wang, H. Harman, G.A. Bancke, A. Adamski and M. Wood, Protective Coatings: Processing and Characterization [Proc. Conf.], Hoboken, New Jersey, USA, (3-5 May) The Minerals, Metals, and Materials Soc., 420 Commonwealth, Pennsylvania 1508£, USA, (Met. A, 9102-72-0096), (1990) 155.

68. D.N. Assanis, Int. J. Mater. Prod. Technol., 4(3), 232 (1989).

69. S. Sturbse, G. Bartuli, N. Zaechetti, R. Dal Maschio, M. Berardo, High Performance Ceramic Films and Coatings [Proc. Conf], Montecatine Ternce, Italy, (27-30 June) Elsevier Science Publishers, Amsterdam, The Netherlands, (Met. A, 9211-72-045), (1991) 353.

70. Udaya Rao, DoD-NASA-DOE-FAA, Alliance Workshop \#7 on Propulsion and Power Systems ( $2^{\text {nd }}$ May) 2002. 